\title{
Effect of Viscosity on the GTA Welds Bead Penetration in Relation with Surface Tension Elements
}

\author{
Kamal Touileb \\ Department of Mechanical \\ Engineering \\ Prince Sattam Bin Abdulaziz \\ University \\ Al-Kharj, Saudi Arabia \\ touilebk@yahoo.com
}

\author{
Rachid Djoudjou \\ Department of Mechanical \\ Engineering \\ Prince Sattam Bin Abdulaziz \\ University \\ Al-Kharj, Saudi Arabia \\ djoudjour@yahoo.com
}

\author{
Abousoufiane Ouis \\ Department of Mechanical \\ Engineering \\ Prince Sattam Bin Abdulaziz \\ University \\ Al-Kharj, Saudi Arabia \\ absoufiane@hotmail.com
}

\begin{abstract}
The aim of this paper is to study the effect of the viscous dissipation on the surface tension and its role on the shape of weld pool. Experiments were conducted on four different casts of ferritic stainless steel with different content in the sulfur and titanium. The results show in particular that the presence of titanium solid compounds affects the role of sulfur as surfactant element. Titanium in the presence of carbon and oxygen, titanium forms solid compounds which affect the Marangoni convection due to the sulfur element in the weld pool. The viscous dissipation due to these compounds alters the flow rate of the molten metal. We expect that the viscosity of metal liquid was altered by these solid compounds. The viscous dissipation due to these compounds contributes to heat the molten metal leading to larger weld bead.
\end{abstract}

Keywords-GTA welding; Marangoni; viscosity; ferritic stainless steel; solid compounds; hardness

\section{INTRODUCTION}

Gas tungsten arc welding (TIG welding or GTAW) is the process of welding used extensively for the last several decades as one of the most commonly used joining techniques for various metallic structures including ships, airplanes, automobiles, bridges, pressure vessels, etc [1-9]. TIG is a process in which the joining of metals is produced by heating therewith an arc between a tungsten (non-consumable) electrode and the workpiece. A shielding gas is also used. The weld bead is very sensitive to chemical composition of the base metal [1, 3-4, 6-7]. Cast-to-cast variations in base material compositions lead to different weld shape $[2,6]$. The theory based on Marangoni convection attests that the active surface elements such as oxygen or sulfur in the molten pool change the fluid flow patterns by altering the surface tension gradient [5]. The surface tension temperature gradients of pure metal are invariably negative, the flow of the molten weld pool motion is directed from the center towards the edge; consequently the weld bead is wide and the deep is shallow [5, 7-9]. The presence of surface active elements such as sulfur or oxygen has a noticeable effect on the surface tension in the sense that the surface tension increases with temperature. Moreover, the surface tension temperature gradient becomes positive, leading to a narrower and deeper weld shape.

In the this paper, the effect of solid compounds on the weld shape is been investigated; the presence of solid compound alters the flow of molten metal in sense that it affects the role of the Marangoni convection. The increase of viscosity increases the viscous stresses between layers of molten metal in weld pool. The micro-hardness value of the welded zone has been measured at the cross section to understand the changes in mechanical properties of the welded zone. Scanning Electron Microscope (SEM) analysis has been carried out on the top of weld zone to detect the main element present in the solid compounds. This study reveals that titanium, carbon and oxygen were the main elements in the solid film.

\section{EXPERIMENTAL PROCEDURE}

Experiments were carried out on four different casts of ferritic stainless steel plates of $1.75 \mathrm{~mm}$ thick using gas tungsten arc welding (GTAW) with automatic welding speed equipment. Welding parameters used in the present work are given in Table I. Chemical compositions of the four different casts are given in Table II. Metallurgical characteristics of the welds were determined by metallographic analyses and microhardness measurements. All specimens were prepared by mechanical grinding and polishing, followed by etching in a solution of $2 \%$ nitric acid HNO3. Hardness profiles were plotted in the weld bead in two orthogonal directions, one being parallel to the plane of the plate and the other perpendicular to that plane and inside the fusion zone as shown in Figure 1.

TABLE I. WELDING PARAMETERS

\begin{tabular}{|c|c|}
\hline Parameters & Value \\
\hline Welding current & $100 \mathrm{~A}$ \\
\hline Travel speed & $50 \mathrm{~cm} / \mathrm{min}$ \\
\hline Gas flow rate & $101 / \mathrm{min}$ \\
\hline Shielding gas & Argon \\
\hline Arc length & $1 \mathrm{~mm}$ \\
\hline Nozzle piece distance & $1 \mathrm{~mm}$ \\
\hline
\end{tabular}


TABLE II. CHEMICAL COMPOSITION OF THE STAINLESS STEEL SAMPLES

\begin{tabular}{|c|c|c|c|c|}
\hline $\begin{array}{c}\text { Samples } \\
\text { elements }\end{array}$ & A & B & C & D \\
\hline Elements & & & & \\
\hline C \% & 0.019 & 0.011 & 0.010 & 0.001 \\
\hline Si \% & 0.32 & 0.29 & 0.37 & 0.30 \\
\hline S \% & 0.002 & 0.006 & 0.002 & 0 \\
\hline P \% & 0.017 & 0.019 & 0.024 & 0.018 \\
\hline Mn \% & 0.43 & 0.46 & 0.43 & 0.424 \\
\hline Cr \% & 17.40 & 17.72 & 17.76 & 17.60 \\
\hline Ni \% & 0.15 & 0.28 & 0.22 & 0.130 \\
\hline Mo \% & 0.022 & 0.024 & 0.23 & 0.010 \\
\hline Ti \% & 0.618 & 0.567 & 0.469 & 0.110 \\
\hline N \% & 0.01 & 0.012 & 0.015 & 0.008 \\
\hline Cu \% & 0.01 & 0.024 & 0.028 & 0.033 \\
\hline Al \% & 0.025 & 0.014 & 0.026 & 0.022 \\
\hline Sn \% & 0.012 & $<0.005$ & 0.009 & 0 \\
\hline Pb \% & 0.001 & 0.0005 & 0.001 & 0 \\
\hline
\end{tabular}

The measures in the horizontal direction were performed at a distance of $0.075 \mathrm{~mm}$ of the surface and the 25 points have been measured with a range of 0.5 to $1 \mathrm{~mm}$ between two successive points. In the vertical direction 7 measuring points have been performed with a range of 0.05 to $0.1 \mathrm{~mm}$ between two successive points. All measures were performed under an indentation load of $200 \mathrm{~g}$. A SEM was used to determine the major elements in solid film. The measures were carried out at different points on the surface of weld bead as shown in Figure 2.

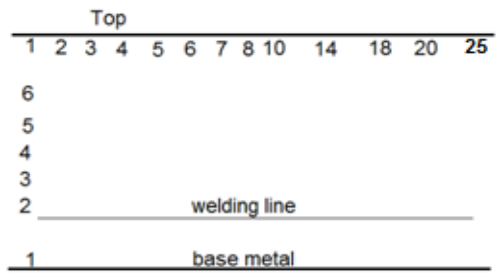

Fig. 1. Different points of micro-hardness measure in two orthogonal directions.

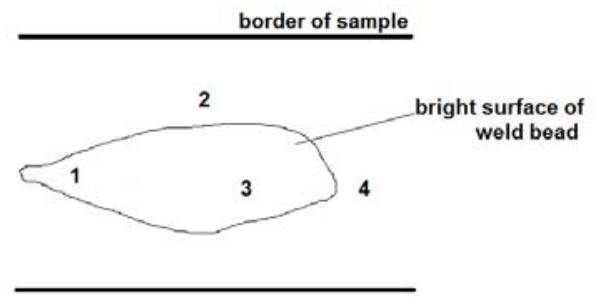

Fig. 2. Points of measures on the top of weld bead.

\section{RESULTS AND DISCUSSION}

\section{A. Weld shape morphology}

The weld morphology is characterized by the penetration depth D and bead width W. Table III shows the geometric parameters of the ferrite stainless steel welds produced with different specimens. The welds exhibit a significant variation in

weld depth and bead width. Welds of specimen B, C and D created partial penetrated beads (Figure 3a), while the weld with specimen A created a full penetrated weld bead (Figure $3 b)$.

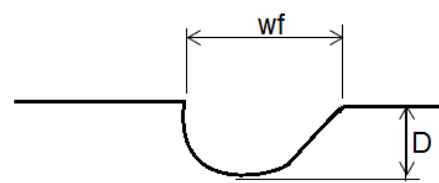

(a): Partial penetrated weld bead

Fig. 3. Weld bead morphology.

TABLE III. GEOMETRIC PARAMETERS OF DIFFERENT CASTS

\begin{tabular}{|c|c|c|c|c|}
\hline & A & B & C & D \\
\hline Wf (mm) & 3.22 & 2.96 & 3.10 & 3.19 \\
\hline D (mm) & full penetration & 1.36 & 1.26 & 0.86 \\
\hline Wb (mm) & 1.77 & - & - & - \\
\hline
\end{tabular}

Although the weld beads of the four casts were obtained under the same conditions, different penetration depths were observed. The possible explanation of these results is associated with the presence of some elements in the weld pool. Cast A presents the widest weld bead, the largest size of the weld shape geometry and is the richest cast on titanium. The formation of solid compounds increases the viscosity of the weld pool which leads to the increase of viscosity stresses between layers. Consequently there is more heat and the weld is fully penetrated. Cast D which is poor on titanium and without trace of sulfur presents the lowest penetration depth. Cast $D$ reacts as the pure metal with negative thermal gradient of surface tension. Without presence of surface tension element the molten weld pool flows from the center point toward the edge and the shape is wider. This cast is poor on $\mathrm{Ti}$ so the formation of solid compound is negligible and the effect of viscous stresses on Marangoni convection is negligible too. Cast $\mathrm{C}$ behaves like pure metal generating outward flow in the weld pool but the high level presence of titanium $(0.469 \%)$ alters the Marangoni convection. Cast B which is the most rich on sulfur $(0.006 \%)$ shows a deep penetration (comparatively to casts $\mathrm{C}$ and $\mathrm{D}$ ). The presence of sulfur generates the inward molten flow. However, the high quantity of titanium leads to the formation of solid compounds which alter the Marangoni convection, consequently the penetration is partial.

B. Effect of welding conditions on the formation of solid compound on surface of weld bead

The tests were carried out on the cast A which is the richest one in titanium. The welding parameters (current intensity I and travel speed V) have been chosen accurately in order to avoid total penetration. Identification of solid compounds nature has been carried out by varying the welding speed. In order to identify the nature of solid compounds, welding speed has been increased to permit the apparition of solid film on the weld bead surface. By moving with high speeds, the front arc welding is slightly deformed as shown in Figure 4 . Therefore 
oxygen is drawn into the weld pool. The oxygen reacts with the elements present in the weld pool and forms solid compounds.

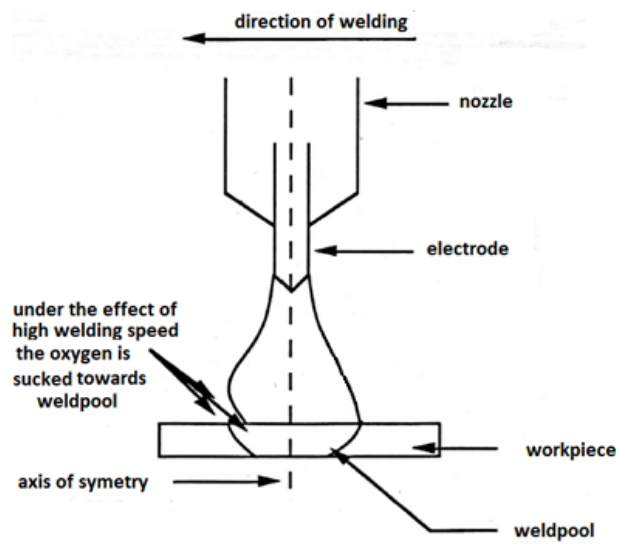

Fig. 4. Deformation of the front arc welding by increasing welding speed.

In Table IV, Y means appearance of solid compound and $\mathrm{N}$ means that solid compound is not visible at the surface. As shown in Table IV, the solid compound appears with a welding current intensity of $100 \mathrm{~A}$ at a travel speed of $80 \mathrm{~cm} / \mathrm{min}$. Using a current intensity of 150 A the solids compounds appears at $70 \mathrm{~cm} / \mathrm{min}$. High energy input due to high welding current intensity induces a fast formation of the solid film.

TABLE IV. PARAMETERS WHICH PERMIT THE APPEARANCE OF FILM ON TOP OF WELD BEAD.

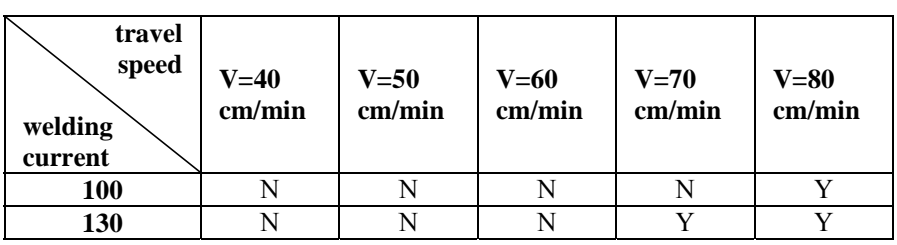

\section{Hardness measurement}

Micro-hardness profiles obtained across parallel and vertical beads are respectively shown in Figure 5 and Figure 6. From these profiles it is observed that as the indentor traverses near the solid film, micro-hardness increases from 140 to 210 HV. These results confirm that this layer of solid compound contributes to the increase of hardness. The possible reason could be associated to the composition of this film which is probably rich on $\mathrm{T}, \mathrm{TiO}, \mathrm{TiO}_{2}$ and $\mathrm{Ti}$.

\section{SEM analysis}

The measures were taken at points $(1,2,3$, and 4$)$ as shown in Figure 7. Results presented in Table V show that the bright layer (points 1 and 3 ) is rich on titanium comparatively to points (2 and 4) far from layer appearing on the surface. This analysis confirms the above prediction and the layer is rich of titanium solid compound.

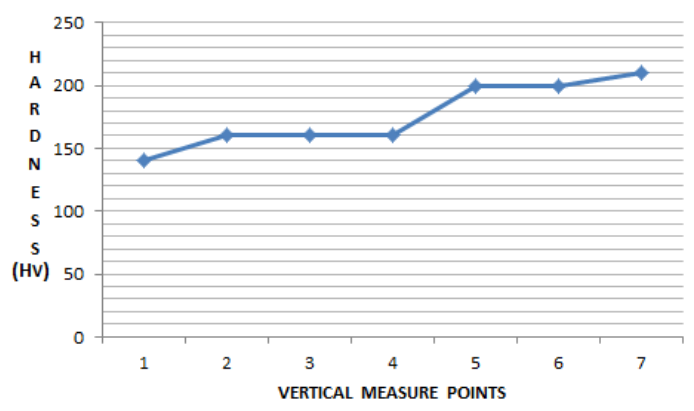

Fig. 5. Vertical hardness measure from the bottom to the top of weld bead.

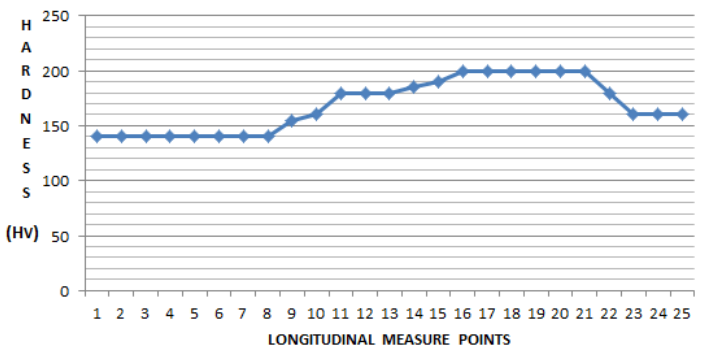

Fig. 6. Longitudinally hardness measure at the top weld bead.

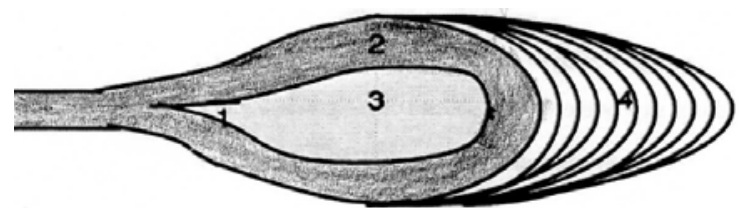

Fig. 7. Points of measure on the top of weld bead.

TABLE V. SEM ANALYSIS RESULTS ON THE SURFACE OF WELDING LINE.

\begin{tabular}{|c|c|c|c|c|}
\hline region & $\mathrm{Fe} \%$ & $\mathrm{Cr} \%$ & Ti\% & Mn\% \\
\hline 1 & 80.67 & 17.70 & 1.03 & 0.6 \\
\hline 2 & 80.56 & 17.91 & 0.84 & 0.67 \\
\hline 3 & 80.51 & 17.86 & 1.03 & 0.59 \\
\hline 4 & 80.37 & 17.91 & 0.92 & 079 \\
\hline
\end{tabular}

\section{CONCLUSION}

The basic conclusions are given below:

- $\quad$ Cast with no sulfur and low titanium content behaves like pure metal in the sense that the formation of solid compounds is negligible and the flow is principally generated by the Marangoni convection. The flow circulation is oriented from the center to the edge of the weld pool leading to a wider and less deep weld bead.

- Cast with high level content of titanium and poor level of sulfur gives a full penetrated weld bead with large back width. In this case the formation of solid compound increases the viscosity of molten weld pool. As a result the friction between layers increases and generates more heat. 
- Cast with high level of both titanium and sulfur gives a weld pool size in between of the above cases. The presence of solid compounds alters the effect of the inward convection flow due to the presence of sulfur.

- The hardness has a higher value (about $210 \mathrm{HV}$ ) near the layer film solid and decreases to $140 \mathrm{HV}$ far from this layer.

- SEM analysis reveals that the solid film is rich on titanium, oxygen and carbon.

- The compounds are characterized by a very high dissociation temperature which exceeds the temperature in the weld pool. Thus, they remain in the weld pool during the welding operation forming solid films.

\section{REFERENCES}

[1] C. R. Heiple, J. R. Roper, "Mechanism for minor element effect on GTA fusion zone geometry", Welding Research, Vol. 61, No. 4, pp. 97-102, 1982

[2] C. R. Heiple, J. R. Roper, "Interaction between impurities and welding variables in determining GTA weld shape", Welding Journal, Vol. 65, No. 6, pp. 150-155, 1986

[3] S. Marya, A. Shahab, K. Touileb, "Effect of minor chemistry elements on pulsed gas tungsten arc weld profiles", Welding, Joining, Coating and
Surface Modification in Advanced Materials (Proc. Pre-Assem. Symp. of 47th IIW Ann. Assem.), Dalian, China, pp. 91-97, 1994

[4] S. Marya, K. Touileb, J. Binard, "Effect of minor chemistry variations on the laser melts profiles of two stainless steels", International Conference on Welding and Melding by Electron and Laser Beams, France, pp. 267-274, June 14-18, 1993

[5] K. Touileb, J. M. A. Dandachi, "Modeling of arc welding in relation with surface tension, viscosity and lorentz electromagnetic forces", 2nd Saudi Technical Conference and Vocational Training, pp. 26-30, Kingdom of Saudi Arabia, 2002

[6] A. Traidia, F. Roger, J. Schroeder, E. Guyot, T. Marlaud, "On the Effects of Gravity and Sulfur Content on the Weld Shape in Horizontal Narrow Gap GTAW of Stainless Steels", Journal of Materials Processing Technology, No. 7,No. 213, pp. 1128-1138, 2013

[7] O. Savytsky, M. Savytsky, D. Bajić, Y. Shkrabalyur, "Influence of the Impurities On The Depth of Penetration With Carbon Steel Welding", METALURGIJA, Vol. 53, No. 2, pp. 167-170, 2014

[8] K. S. Prasad, C. S. Rao, D. N. Rao, "An Investigation on Weld Quality Characteristics of Pulsed Current Micro, Plasma Arc Welded Austenitic Stainless Steels", International Journal of Engineering, Science and Technology, Vol. 4, No. 2, pp. 159-168, 2012

[9] D. Li, S. Lu, W. Dong, D. Li, Y. Li, "Study of the Law Between the Weld Pool Shape Variations With the Welding Parameters Under Two TIG Processes", Journal of Materials Processing Technology, Vol. 212, No. 1, pp. 128-136, 2012 